\title{
La independencia hispanoamericana en el pensamiento de José Martí
}

Hispanic-American Independence in Marti's thought

\section{A independência hispano-americana no pensamento de José Martí}

Carlos Rodolfo González-Zúñiga

Instituto Tecnológico

Costa Rica

Recibido: 13/04/2021 - Aceptado: 20/05/2021

Resumen

Se analiza la interpretación de José Martí sobre los procesos de independencia hispanoamericanos. La primera parte menciona la crítica martiana sobre elementos coloniales que perviven en las nuevas repúblicas; el carácter autónomo del proceso de independencia, y la propuesta de una segunda independencia. Posteriormente se analiza el concepto de hombre natural para interpretar, en la obra Patria y Libertad, el papel de los sectores sociales populares indígenas y mestizos como los sujetos revolucionarios, en el marco de la lucha independentista de Guatemala frente al colonialismo español. Asimismo, se analiza una crítica hacia el contexto liberal de la obra Patria y Libertad y se presentan dos reflexiones sobre el teatro que incorporan el valor de la territorialidad en la teatralidad. Se concluye que la obra Patria y Libertad expresa el papel de la interculturalidad y los protagonismos de sectores sociales populares en el desarrollo de la segunda independencia.

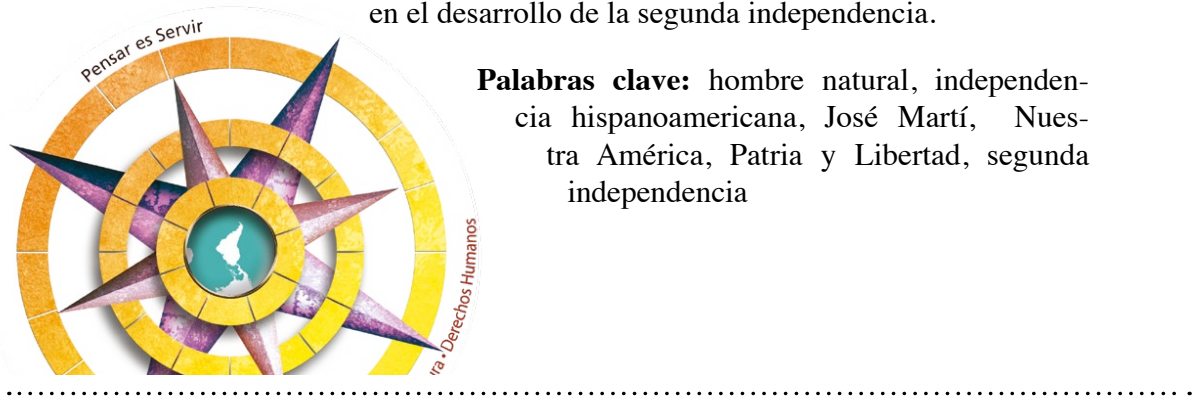

Doi: https://doi.org/10.15359/tdna.37-70.3 


\begin{abstract}
José Martí's interpretation of the Hispanic American independence processes is analyzed in this article. The first part mentions Martí's criticism of colonial elements that survive in the new republics; the autonomous character of the independence process, and the proposal of a second independence. Following the analysis, the concept of natural man is used to understand the role of the popular indigenous and mestizo social sectors as revolutionary subjects in the framework of Guatemala's independence struggle against Spanish colonialism in the work Patria y Libertad [Homeland and Freedom]. Likewise, a critique of the liberal context of the play Patria $y$ Libertad is analyzed and two considerations on theater that incorporate the value of territoriality in theatricality are presented. Finally, it is concluded that the play Patria y Libertad expresses the role of interculturality and the leading role of popular social sectors in the development of the second independence.
\end{abstract}

Keywords: hispanic american independence, Patria y Libertad [Homeland and Freedom], José Martí, natural man, Nuestra América [Our America], second independence

Resumo

É analisada a interpretação de José Martí sobre os processos de independência hispano-americanos. A primeira parte menciona as críticas de Martí aos elementos coloniais que sobrevivem nas novas repúblicas; o carácter autónomo do processo de independência, e a proposta de uma segunda independência. Na segunda parte da análise, o conceito de homem natural é utilizado para interpretar na obra Patria y Libertad o papel dos sectores populares indígenas e mestiços sociais como sujeitos revolucionários no quadro da luta pela independência da Guatemala contra o colonialismo espanhol. Do mesmo modo, é analisada uma crítica do contexto liberal da peça Patria y Libertad [Pátria e Liberdade] e são apresentadas duas reflexões sobre o teatro que incorporam o valor da territorialidade na teatralidade. Finalmente, conclui-se que a peça Patria y Libertad exprime o papel da interculturalidade e o protagonismo dos sectores sociais populares no desenvolvimento da segunda independência.

Palavras chave: homem natural, independência hispânica americana, José Martí, Nuestra América [Nossa América], Patria y Libertad [Pátria e Liberdade], segunda independência 


\section{La interpretación martiana sobre la independencia de Hispanoamérica}

La invasión cultural que sufrió América a partir de la conquista y la colonia se perpetuó durante siglos, y no desapareció con los procesos de independencia. A finales del siglo XIX, para José Martí es necesario combatir el colonialismo en todas sus transfiguraciones filosóficas, religiosas, culturales, políticas y económicas. Martí (2002) plantea cómo:

El continente descoyuntado durante tres siglos por un mando que negaba el derecho del hombre al ejercicio de su razón, entra, desatendiendo o desoyendo a los ignorantes que lo habían ayudado a redimirse, en un gobierno que tenía por base la razón; la razón de todos en las cosas de todos, y no la razón universitaria de unos sobre la razón campestre de otros. El problema de la independencia: no era el cambio de formas, sino el cambio de espíritu. (p. 19)

Este argumento expresa la comprensión martiana de que el colonialismo negaba el ejercicio racional de los hombres americanos, y, a su vez, expresa el valor de un nuevo carácter en la racionalidad humana, el cual no reproduzca elementos de dominación, sino que contemple todas la experiencias de humanidad y no degrade el estatus de unos sobre otros; Martí no apoya la «razón universitaria» sobre la «razón campestre» sino que su propuesta concibe una racionalidad con características universales, «la razón de todos en las cosas de todos». En este sentido, la racionalidad no debe utilizarse como un criterio de dominación cultural por parte de pueblos y sujetos «racionales» sobre pueblos y sujetos «irracionales». La filosofía martiana es inclusiva y concibe la independencia como un proceso que, necesariamente, debe cambiar «el espíritu» de los pueblos hispanoamericanos, esto es, una independencia que vaya más allá del cambio de formas y estructuras de gobierno, donde pueda surgir una verdadera sensibilidad humana americana con elementos universalizables para la humanidad.

Con la independencia, los pueblos hispanoamericanos alcanzaron una libertad geopolítica formal que transforma el proceso cultural americano, pero el imaginario colonial no desaparece del todo, pervive interiorizado en las relaciones económicas y culturales que siguieron operando con lógicas de 
explotación, subordinación y discriminación. Martí percibe que los procesos de independencia no han sido plenos y propone que: "De la tiranía de España supo salvarse la América española; y ahora, después de ver con ojos judiciales los antecedentes, causas y factores del convite, urge decir, porque es la verdad, que ha llegado para la América española la hora de declarar su Segunda Independencia” (Martí, 2002b, p. 46).

La categoría de segunda independencia surge en el pensamiento martiano como referente de un proceso constante de independencia cultural para los pueblos hispanoamericanos. En la construcción de ese proceso es necesario para Martí crear formas de pensamiento y sensibilidad que luchen contra el colonialismo e imperialismo y sus formas de transfiguración. Martí percibe que la situación de los pueblos americanos remite a un campo de lucha ideológico. Al respecto menciona que "Trincheras de ideas valen más que trincheras de piedra (...) No hay proa que taje una nube de ideas. Una idea enérgica, flameada a tiempo ante el mundo, para, como la bandera mística del juicio final, a un escuadrón de acorazados" (Martí, 2002e, p. 15). Ese es uno de los flancos de lucha cultural que abre José Martí, la lucha por una sensibilidad e idearios que permitan pensar América Latina desde sí misma, y no bajo un modelo de racionalidad y sensibilidad impuesto. El imaginario impuesto y centrado en la superioridad europea construyó la otredad de los pueblos americanos ignorando y cortando su historia, para reinventarla como las propias de pueblos sometidos. Martí propone realizar un «cambio de espíritu» y crear sentimientos e ideas liberadoras de esa conquista ideológica, económica y política, para poder crear también nuevas identidades americanas que se asuman desde sus conflictividades y puedan autoproducir formas de integración y criticidad social, arraigadas en sus propios referentes culturales. La segunda independencia es cultural.

Posterior a la independencia siguieron existiendo y reproduciéndose, bajo nuevas condiciones, herencias coloniales en las recientes repúblicas, lo cual sintetiza Martí en el siguiente pensamiento:

La colonia continuó viviendo en la república; y nuestra América se está salvando de sus grandes yerros de la soberbia de las ciudades capitales, del triunfo ciego de los campesinos desdeñados, de la importación excesiva de las ideas y fórmulas ajenas, del desdén inicuo e impolítico de la raza aborigen, -por la virtud superior,

4 La independencia hispanoamericana en el pensamiento de José Martí

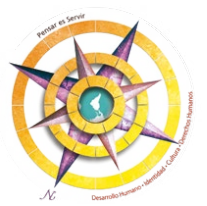


abonada con sangre necesaria, de la república que lucha contra la colonia. (Martí, 2002e, p. 19)

El cubano percibe que los problemas estructurales de Hispanoamérica no se han solventado desde la raíz en las nuevas repúblicas, pues estas reproducen lógicas de dominación económica y cultural donde los territorios independientes y sus habitantes son instrumentalizados como generadores de materias primas para fortalecer las urbes industriales (cf. Agosta, 1984) y fomentar la producción capitalista. Además, posterior a los procesos de independencia, Estados Unidos se constituye como el sucesor del colonialismo económico en la lucha de poder por controlar América (cf. Acosta, 1975) haciendo eco de la falaz incapacidad americana para autogobernarse y mostrando carácter de juez internacional paternalista.

Martí interpreta los procesos de independencia hispanoamericanos con un enfoque autóctono, menciona que: "La independencia de América venía de un siglo atrás sangrando: - ¡Ni de Rousseau ni de Washington viene nuestra América, sino de sí misma!" (Martí, 2002c, p. 244).

Martí señala que la lucha por las independencias hispanoamericanas y su legitimidad fuera del colonialismo, son procesos con características locales, que tratan de liberarse de la explotación de la sociedad europea y transformar su propia identidad desde raíces autóctonas. La gestación de los procesos independentistas hispanoamericanos no puede reducirse a la influencia de la Revolución francesa y la independencia estadounidense, sino que responde a sus propias determinaciones. Pero tampoco está del todo desligada de dichas influencias. En este sentido, el autor Antonio Sebazco (2003) propone que:

En su rescate de la autoctonía americana, Martí contiende con aquellos que explican la emancipación política de nuestra América como resultado mecánico de las revoluciones norteamericana y francesa. Si bien el cubano no desconoce (y en varias ocasiones lo subraya) la influencia de la gesta del $76 \mathrm{y} \mathrm{del}$ 89 en nuestro medio, prioriza en sus análisis el proceso de gestación del movimiento emancipador latinoamericano. (p. 366)

Sebazco pone de manifiesto que la interpretación martiana sobre la independencia de los pueblos latinoamericanos es original y resalta el interés de Martí en el papel de los movimientos emancipadores.

En la cita anterior de Martí, se hace referencia a Rousseau, figura de la 
filosofía social y reflejo de sociohistoria europea; cuya filosofía social no tiene la clave para analizar y resolver los problemas americanos. Señala Martí (2002e) que: "Ni el libro europeo, ni el libro yanqui, daban la clave del enigma hispanoamericano. (...) Cuando aparece en Cojímar un problema, no van a buscar la solución a Dantzig. Las levitas son todavía de Francia, pero el pensamiento empieza a ser de América." (p. 20).

Tampoco Washington representa un referente que permita explicar la construcción de la sociohistoria cultural americana. Latinoamérica viene de sí misma y ha generado condiciones sociales particulares; se ha levantado formalmente de la carga colonial y han configurado repúblicas que todavía reproducen vicios estructurales de la colonial, pero que se construyen con pensamiento cada vez más propio, y, que, por esta misma razón, se hace necesaria y urgente la segunda independencia.

Para Martí es ineludible crear soluciones propias a problemas propios, no es válido tratar de mejorar las sociedades latinoamericanas con fórmulas culturales, económicas y políticas foráneas, pues no permiten autoconstruir la sociedad con raíces propias y profundas. De aquí no se sigue que sean despreciables los intercambios con el mundo exterior a América, y sus eventuales aportes, sino que estos aportes externos serán un buen abono para un tronco cultural, económico y político propio americano. Sobre este aspecto, la idea central de Martí es: "Injértese en nuestras repúblicas el mundo, pero el tronco ha de ser de nuestras repúblicas" (2002e, p. 18), lo cual muestra que el cubano no se cierra a un solipsismo cultural, él no considera que todo lo exterior sea dañino para la autonomía americana, pero el tronco autóctono debe ser el eje de la cultura y de las luchas revolucionarias.

\section{El hombre natural como hom- bre político en la obra Patria y Libertad}

La obra dramática Patria y libertad (Drama Indio) -escrita por Martí, a pedido del gobierno guatemalteco para conmemorar la independencia en 1877- expresa una recreación del proceso de independencia de Guatemala, pero la obra también va más allá del simple motivo conmemoratorio y expresa el posicionamiento martiano en torno a los actores sociales de la independencia, siendo los actores principales, personajes que podríamos identificar como hombres naturales.

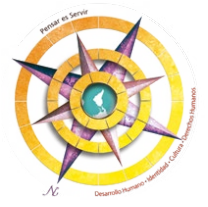


Los acontecimientos de la obra $P a$ tria y Libertad son un claro ejemplo de las ideas martianas referentes de la noción de hombre natural como expresión de los diversos sectores populares y su papel en la lucha independentista. El texto en sus personajes ejemplifica el papel del hombre natural como sujeto revolucionario. Para Martí (2002e):

Viene el hombre natural, indignado y fuerte, y derriba la justicia acumulada de los libros, porque no se la administra en acuerdo con las necesidades patentes del país. Conocer es resolver. Conocer el país, y gobernarlo conforme al conocimiento, es el único modo de librarlo de tiranías. (p. 18)

En la cita anterior, la propuesta antropológica y política del hombre natural se presenta como un proceso de conocimiento situado en las condiciones autóctonas, como fundamento del quehacer político. En Patria y Libertad los sectores populares son los principales organizadores de la lucha independentista, en la cual se expresa toda la fuerza y la indignación necesaria para derribar el antiguo régimen colonial, $\mathrm{y}$, al mismo tiempo, estructurar una forma de gobierno acorde a los problemas propios del país.
Nuestra interpretación del texto $P a$ tria y Libertad postula a los sectores populares representados en la obra como sujetos sociales y políticos que asumen la tarea revolucionaria de construir una patria nueva, libre de tiranías. Martí da características del hombre natural como sujeto social revolucionario triunfante en el devenir de América, dice: "el libro importado ha sido vencido en América por el hombre natural. Los hombres naturales han vencido a los letrados artificiales. El mestizo autóctono ha vencido al criollo exótico." (Martí, 2002e, p. 18). El cubano deja claro que los conocimientos importados son secundarios para comprender la realidad latinoamericana, todo conocimiento debe ser apropiado mediante el diálogo y la crítica desde las raíces sociales de cada pueblo.

La noción de hombre natural se contrapone a la noción de letrado artificial, los sectores populares en la concepción martiana son el referente de autoconocimiento cultural y autoctonía americana frente a los letrados artificiales, que buscan su identificación cultural en referentes extranjeros, estos serían los reproductores internos del proceso de colonización del mundo de la vida en las sociedades latinoamericanas, donde las estructuras vivenciales de los imperios coloniales se imponen, y encubren y 
degradan como inferiores las formas de estar en el mundo de los pueblos originarios y mestizos. Los hombres naturales son los actores sociales y políticos que priorizan las condiciones autóctonas y mestizas del mundo de la vida, dando así un equilibrio a la construcción de las sociedades. Las estructuras vivenciales de los pueblos autóctonos y mestizos brindan un aporte enriquecedor y potencian el crecimiento humano de las sociedades latinoamericanas desde la autodeterminación de su forma de estar en el mundo.

La figura del mestizo autóctono es otra forma de referirse al sentido del hombre natural, el cual reconoce las condiciones diversas de su entorno y trata de equilibrar las relaciones sociales. Esto podemos verlo reflejado en la obra Patria y Libertad en el personaje de Martino, el cual se muestra como un mestizo autóctono que vence a los criollos exóticos representados en el personaje de Don Pedro. Otros personajes como las indígenas Coana, Indiana, el indio, el pueblo, y el criollo Pedro también expresan el sentido del hombre natural. En la propuesta martiana los sectores populares mestizos se articulan en lo social y político desde su multiculturalidad y, en este sentido, la reflexión martiana sobre la gesta independentista parte de la multiculturalidad de los pueblos latinoamericanos, $y$, por consiguiente, en nuestra interpretación proyectiva hacia la segunda independencia la multiculturalidad es un criterio indispensable.

La obra Patria y Libertad es una creación ficcional que permite interpretar el gran peso revolucionario que Martí proyecta sobre los sectores populares, indígenas y mestizos; estos son los referentes revolucionarios, contrario a los sectores dominadores identificados por Martí en los personajes coloniales.

La trama del texto es la lucha por la independencia, consiste en la tensión existente entre los colonos representantes de España y los sectores sociales que luchan por la independencia, que en Guatemala son mayoritariamente indígenas y mestizos. La obra es una propuesta dramática que problematiza las relaciones amorosas de la indígena Indiana y el mestizo Martino, estatuyendo una suerte de axiología política revolucionaria jerarquizada, donde la necesidad más imperiosa es conseguir la independencia antes que el matrimonio.

Una primera tensión social abre la obra, las indígenas Coana e Indiana tienen una discusión con las señoras españolas Doña Casta y Doña Fe.

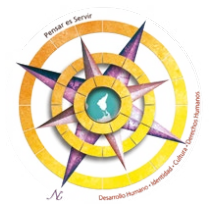


El texto es el siguiente:

LA CAMARISTA. Mi señora, la noble doña Casta, terminada la misa, hacia aquí llega.

(Enérgica, a las indias:)

Retiraos; que se acerca mi señora y no quiere encontrar gente plebeya. Retiraos.

INDIANA. Y ¿por qué? La calle es libre. Y, esta calle, calle es de nuestra tierra.

Que aunque nosotras somos de la plebe y doña Casta es de la noble$\mathrm{za}$, nosotras somos hijas de este suelo y ella no es nada más que una extranjera.

\section{Escena III}

Doña casta sale de la iglesia, seguida del padre Antonio con la compañía de Jesús; y de nobles y caballeros, que la siguen.

DOÑA FE. ¡India insolente!

DOÑA CASTA. Amigas, ¡qué os sucede, amigas?

LA CAMARISTA. Estas indias, señora, que altaneras, con frases injuriosas y agresivas, 1os insultan y ofenden y nos vejan.

DOÑA FE. Y, además, contra España, mi señora, lanzan frases procaces y blasfemias.
DOÑA CASTA. ¡Cómo así os atrevéis, indias malditas, a insultar nuestros fueros de grandeza? ¡Olvidáis que entre ambas, yo y vosotras, existen gran distancia y diferencia?

Mas, ya caigo, ¡eres tú, la india rebelde, amante del mestizo de alma fiera a quien llaman Martino el subversivo, que a la chusma subleva!

PADRE ANTONO. ¿Quién es Martino?

DOÑA CASTA. Un charlatán que tiene teorías absurdas y alma negra. Qué lleva en sus entrañas miserables la ruin carroña de la inmunda lepra. Que odia a España, a Jesús, a nuestra raza, al augusto blasón de la bandera. Un plebeyo envidioso, sin principios, sin honor, sin valor y sin conciencia.

COANA. No: es Martino un valiente y un patriota que lucha por la santa independencia de nuestra patria, que hoy solloza esclava, encadenada por la opresión vuestra. (Martí, 2002f, p. 132-133)

En esta discusión, los personajes colonizadores reflejan posicionamientos ideológicos que degradan la dignidad y el estatuto humano de los sectores populares de la colonia mestiza, al naturalizar la dominación política, pero, por otro lado, se 
muestran argumentos críticos por parte de las indígenas que hacen respetar su carácter legítimo primario sobre las tierras americanas. Este es un ejemplo del posicionamiento crítico que expresan los sectores populares de la obra. La tensión también preanuncia la figura de Martino, como personaje que reivindica el criterio de sujeto humano y político revolucionario, que lucha por la independencia. Llama la atención la similitud del nombre del personaje principal Martino con el de Martí; ciertamente en el personaje de Martino refleja las posiciones liberadoras de Martí.

La cita anterior expresa el rebajamiento ideológico hacia los indígenas, como también la sensibilidad colonizadora, la cual se asienta en conceptos como el de raza, el cual Martí descalifica enérgicamente ${ }^{1}$. Martí refleja en su obra la división social y las tensiones internas de la sociedad guatemalteca, en dicha

1 Debe recordarse que según Martí (2002e) “No hay odio de razas, porque no hay razas. Los pensadores canijos, los pensadores de lámparas, enhebran y recalientan las razas de librería, que el viajero justo y el observador cordial buscan en vano en la justicia de la Naturaleza, donde resalta en el amor victorioso y el apetito turbulento, la identidad universal del hombre. El alma emana, igual y eterna, de los cuerpos diversos en forma y en color. Peca contra la Humanidad el que fomente y propague la oposición y el odio de las razas" (p. 22) sociedad los personajes coloniales muestran y encubren su carácter dominador, mientras que los sectores populares autóctonos, indígenas y criollos, comunican su proyección liberadora. Un tema que resulta notable es la trama amorosa que presenta el drama; la relación entre Martino y Coana no se formalizará hasta que se logre concretar la independencia, dicha situación es una oportunidad para que Martí exponga, de forma creativa, su sensibilidad hacia los problemas de mundo en la vida de las sociedades mestizas. La posición de Martí expone dramáticamente que, los pueblos mestizos tienen como prioridad axiológica la lucha liberadora, a su vez que, los compromisos afectivos muestran la validez del amor como motivo para luchar. El amor subjetivo hacia la pareja se expresa como amor a la libertad e independencia, lo cual es parte de una experiencia ética revolucionaria, donde la jerarquía de necesidades determina la acción política y humana.

La obra muestra que la fuerza de los sectores populares aumenta cuando se articulan los diversos colectivos con exigencias liberadoras, Martí expresa su mensaje de resistencia, con características éticas, dice:

Españoles, soldados, etc., avanzan contra el pueblo que,

10 La independencia hispanoamericana en el pensamiento de José Martí Carlos Rodolfo González-Zúñiga

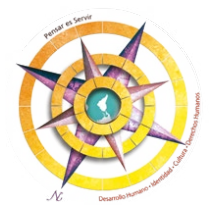


replegándose, toma escena hacia el lado opuesto, cuando aparece Martino.

MARTINO. Quietos todos. No huyáis ante los déspotas. Quietos aquí. ¡Lo manda nuestra América! (Martí, 2002f, p. 139)

Esta cita muestra el señalamiento imperioso de no dejar avanzar más los intereses colonialistas y plantarse firmes ante el despotismo como una exigencia ética, "Lo manda nuestra América" dice Martí, para dejar claro que constituye una necesidad ético-política resistir y combatir el despotismo en pos de articular la creación de «Nuestra América» mestiza. Más adelante agregará Martino: "Por libertad y dignidad marchamos. Nuestros hermanos son los que la invocan." (Martí, $2002 \mathrm{f}$. p.146). Y, de esta manera, el proyecto articulador martiano se abre a todos aquellos diversos colectivos que luchen por la libertad y la dignidad desde raíces propias, en una articulación con una proyección de sensibilidad fraternal que estimule la lucha por la segunda independencia.

El estudioso martiano Pedro Pablo Rodríguez, en su artículo el poema de 1810, habla de algunas ideas centrales en el pensamiento martiano que se reflejan en la obra Patria y Libertad:
Estas ideas centrales son que las independencias no se hubieran alcanzado sin la participación masiva de los sectores populares en su favor y sin la acción unida de las fuerzas patrióticas del continente. Ambas constituirían, a su vez, ideas claves también en su criterio acerca de la revolución anticolonial que estaba pendiente en Cuba, tarea en la que se empeñó plenamente. (Rodríguez, 2012. p. 42)

Rodríguez pone de manifiesto que la revolución social propuesta por Martí tiene características populares que abarcan todos los actores sociales de los pueblos americanos. Apegado a la constitución cultural propia del pueblo guatemalteco, Martí enfoca una problemática vital de esta sociedad, como lo es la articulación de los múltiples pueblos indígenas y mestizos, esto queda evidenciado en el mismo subtítulo de la obra, que:

(...) no por casualidad, lleva por subtítulo el de Drama indio: desde ese encabezamiento queda claro que para el joven exiliado cubano la independencia era asunto también de los pueblos originarios, no solo de los blancos... el desarrollo de la trama y sus personajes muestran que para Martí aquellos pueblos autóctonos desempeñaron un papel protagónico en la historia... Lo interesante es que en verdad son Martino y el 
Indio, y en menor medida el criollo Pedro, los personajes en escena que lideran el movimiento patriótico y obligan a retirarse a los representantes del colonialismo, identificados como un sacerdote, un noble y los funcionarios de la Corona española. (Rodríguez, 2012.p. 44)

La obra Patria y Libertad es un claro ejemplo de la proyección martiana de los pueblos indígenas y mestizos, como sujetos éticos-políticos autogestionantes de la independencia, aunque históricamente los pueblos autóctonos no fueron los principales protagonistas de las independencias formales. La cuota revolucionaria que Martí otorga a los pueblos indígenas y mestizos da indicios sobre el papel protagónico que él anhela para los pueblos autóctonos indígenas y mestizos, en función de la segunda independencia.

Al finalizar la obra, ya conseguida la independencia, el personaje de Martino expone su proyección sobre el futuro, Dice Martino:

Martino. ¡Libres, libres como el quetzal! ¡Libertad santa! Patria libre... Coana... esposa mía...

La inmensa procesión que se levanta, marca la feliz ruta del futuro. Ya veo el porvenir que se agiganta. Ya veo el porvenir amplio y seguro. Hombres libres serán los descendientes de tu amor y del mío. Y Patria y Libertad honren valientes nietos de Cuauhtémoc y Hatuey, con nobles bríos.

A sostener por siempre independientes, con las manos, las uñas y los dientes, contra el yugo opresor de las Españas, nuestros dos continentes (...) (Queda Martino abrazado al grupo que forman Coana e Indiana, símbolos de las dos Américas...) (Martí, 2002f, p. 151)

De la cita anterior es importante resaltar el optimismo social que expresa Martino al proyectar un porvenir «amplio y seguro», Martí reconoce que, en las sociedades latinoamericanas, luego de los procesos de independencia formal, perviven múltiples vicios coloniales; esta afirmación que el personaje Martino hace de un porvenir «amplio y seguro», se puede interpretar como una proyección hacia la construcción de la segunda independencia. La primera independencia quedó viciada $\mathrm{y}$, por ende, es necesaria una segunda independencia que permita concretar un porvenir amplio y seguro.

La interpretación que hace Martí de la sociohistoria americana implica una concepción liberadora del futuro. Aún y cuando Martí comprende que en los nuevos estados nacionales

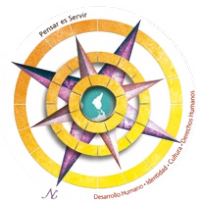


se siguen reproduciendo lógicas de dominación externas e internas, su propuesta implica aceptar que a pesar de esos problemas que perviven, las sociedades latinoamericanas han iniciado el camino de su transformación, por lo tanto, es necesario fortalecer el movimiento de los diversos pueblos para alcanzar una verdadera y efectiva independencia.

En este sentido, Martí plantea: "La manera de celebrar la independencia no es, a mi juicio, engañarse sobre su significación, sino completarla" (Martí, 2002a, p.110). La propuesta martiana es inclusiva y concibe los procesos de independencia como procesos que, necesariamente, deben cambiar «el espíritu» de los pueblos latinoamericanos; esto significa poder construir una independencia más allá de las formas de gobierno, pero este proceso es necesario completarlo, pues las primeras independencias formales quedaron viciadas y para purgar esos vicios es necesario una segunda independencia, entendida esta como un proceso abierto en todos los ámbitos culturales y políticos.

\section{Referencia a un enfoque liberal sobre el texto Patria y libertad}

Según Juan Blanco (2010), la influencia de las posturas liberales de la época hace de Martí un reproductor del discurso hegemónico liberal del gobierno de Rufino Barrios, en torno a las políticas de los pueblos indígenas.

Blanco plantea que Martí inventa la subjetividad indígena resaltando tres aspectos de la influencia liberal, dice:

El indígena inventado en Patria y Libertad parece tener las siguientes características: a) es un personaje empoderado, dueño de sí, y participe del proyecto patrio, b) anticlerical, c) reconoce su papel subalterno frente al bien mayor de la patria. Estas 3 características manifiestan la representación del indígena ideal requerida por la reforma liberal. (Blanco, 2010, p. 17)

La propuesta de Blanco enfoca el posicionamiento martiano frente a los pueblos indígenas como una recreación idealizada de los indígenas, como sujetos políticos con características liberales, que luego de posicionarse críticamente frente a la autoridad gubernamental y eclesial, se auto anula en pos de la patria.

Blanco plantea que la construcción idealizada del indígena en la obra Patria y Libertad está en función de los intereses liberales del gobierno barrista; a nuestro parecer la influencia liberal no se puede pasar por alto, pero tampoco se puede 
reducir la propuesta martiana bajo criterios liberales con características de dominación hegemónicas. Martí no reduce su comprensión del sector popular indígena a los intereses liberales. Las reformas agrarias del gobierno barrista vulneraron los territorios comunales indígenas, $\mathrm{y}$ Blanco reconoce y vincula esto con un pasaje de Patria y Libertad donde la supuesta subordinación del indígena anula su papel como sujeto político empoderado.

Blanco se fundamenta en un diálogo donde el indio se enfrenta al religioso y el pueblo exclama «Viva el indio» y el personaje indígena responde «Yo no, la patria libre». Esta referencia que Blanco tomó como subordinación, no se interpreta en este trabajo como tal; a nuestro juicio el sentido de este diálogo expresa la articulación de los diversos movimientos sociales en la producción de la patria. No consideramos esto una auto anulación del indígena en pos del bien patrio, sino una proyección martiana sobre la articulación de los sectores populares en la construcción de la patria; en este caso, el sector indígena se articularía con los demás sectores populares, afrocaribeños y mestizos. La interpretación de Juan Blanco lleva razón en rastrear la influencia liberal de esta época del pensamiento martiano; sin embargo, la sobrevaloración del liberalismo no permite que Blanco reconozca el carácter liberador y articulador de los distintos sectores sociales en la propuesta martiana.

\section{Dos reflexiones sobre teatro}

Martí escribe sobre la obra Patria y Libertad una nota que, al final plantea lo siguiente: "Hay dos teatros: el social, que requiere un arte menor, local y relativo; y el de arte mayor, el teatro de arquetipos. Como hay dos vidas. La que se arrastra, y la que se desea." (Martí, 2002d, p. 154).

\section{La obra Patria y Libertad expresa} características de los dos tipos de teatro, por un lado, contiene elementos locales y relativos a las condiciones propias de la sociedad guatemalteca, pero también expresa un deseo e impulso de organización de los sectores populares con características de modelo revolucionario. Del mismo modo, la sociedad guatemalteca tendría dos tipos de vida cultural, la que arrastra sus vicios locales y específicos, y la vida que se desea como referente revolucionario de los sectores populares.

La obra Patria y Libertad, presenta la proyección del carácter revolucionario de los sectores populares frente a los procesos de las independencias

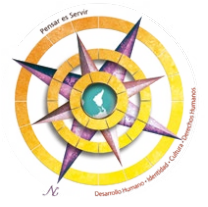


hispanoamericanas y su vigencia en la construcción de la segunda independencia.

La filosofía del teatro que propone Jorge Dubatti, denomina la cartografía teatral, al enfoque teatral basado en conceptualizaciones referente a la territorialidad; en este sentido, se reconoce el valor de la categoría de territorialidad, tal como las define Dubatti (2011): "Llamamos territorialidad a la consideración del teatro en contextos geográficos-histórico-culturales singulares." (p.111). Podemos interpretar la obra Patria y Libertad desde el criterio de territorialidad antes mencionado y establecer cómo las preocupaciones del drama están directamente ligadas a la reconfiguración cultural y a los referentes históricos abiertos por los procesos de independencia hispanoamericanos, esta orientación la hacen sin lugar a dudas una obra que problematiza la territorialidad de Guatemala, pero al mismo tiempo es posible ampliar esta preocupación telúrica de Martí a nivel continental, y considerar la territorialidad de la obra con una intencionalidad hacia Nuestra América. En este aspecto, el texto no responde al teatro cubano o teatro guatemalte$\mathrm{co}$, sino que se inserta como una obra de teatro continental americano que contiene preocupaciones territoriales, culturales, políticas e históricas.
Martí expresa un teatro fundador de una nueva territorialidad abierta a la articulación multicultural: El teatro de Nuestra América.

\section{Conclusiones}

La reflexión de José Martí sobre los procesos de independencia hispanoamericanos refleja una comprensión de dichos procesos desde características propias, donde lo significativo era el cambio de espíritu y no solo la formalización de los estados nacionales. Este cambio de espíritu ha sido un factor pendiente, las nuevas repúblicas han mantenido vicios coloniales que deben purgarse en una segunda independencia que logre ese cambio de espíritu. La obra teatral Patria y Libertad se muestra como un texto que expresa la visión martiana sobre los procesos de independencia hispanoamericanos, $\mathrm{y}$, además, desde nuestra perspectiva, también expresa la proyección de cómo debería articularse una segunda independencia, donde es significativo mencionar el papel de la interculturalidad y el protagonismo de sectores sociales populares que se han identificado con el concepto de hombre natural.

Se puede afirmar la noción de hombre natural como sujeto revolucionario de la segunda independencia en 
la obra Patria y Libertad, en ese sentido el imaginario teatral cumple la función de una proyección identitaria y revolucionaria en la cual triunfa una identidad construida desde la autoctonía telúrica y el respeto a la multiculturalidad.

\section{Referencias bibliográficas}

Acosta, L. (1984). El Barroco de Indias y otros ensayos. La Habana: Casa de las Américas.

(1974). José Martí, la América precolombina y la conquista española. La Habana: Casa de las Américas.

Blanco, J. (2010). Colonialidad del saber y literatura: Invención y anulación del indígena en Patria y Libertad de José Martí. Revista A Parte Rei, número 72. Versión digital descargada el 30/10/2013 de http://biblioteca.universia.net/html_bura/ficha/ params/title/colonialidad-saberliteratura-invencion-anulacion-indigena-patria-libertad-drama-indio/ id/53622424.html

Dubatti, J. (2011). Introducción a los estudios teatrales. D. F. México: Libros de Godot.

Martí, J. (2002a). Obras Completas. Tomo VII, Carta a Valero Pujol, Director de El Progreso. La Habana: CEM.

(2002b). Obras completas. Tomo VI. Congreso internacional de Washington. La Habana: CEM.

. (2002c). Obras completas. Tomo VIII. Discurso pronunciado en la velada de la Sociedad Literaria Hispanoamericana en honor de Simón Bolívar el 28 de octubre de 1893. Patria, Nueva York 4 noviembre 1893. La Habana: CEM.

. (2002d). Obras completas. Tomo XVIII, Nota sobre el Drama indio. La Habana: CEM.

(2002e). Obras completas. Tomo VI. Nuestra América. La Habana: CEM

. (2002f). Obras completas. Tomo XVIII, Patria o libertad. (Drama indio). La Habana: CEM

Rodríguez, P. P. (2012). El poema de 1810, José Martí ante las Independencias Hispanoamericanas. Temas de Nuestra América. Heredia, C. R.: EUNA

Sebazco, A. (2003). El proyecto de modernidad martiano. Repertorio Americano. Nueva Época. N. ${ }^{\circ} 15-16$, enero-diciembre 2003, pp. 366-371.

16 La independencia hispanoamericana en el pensamiento de José Martí Carlos Rodolfo González-Zúñiga 